\title{
Patrimônio imaterial no "Caminhos das Missões": apropriações memoriais ou narrativas coloniais sobre as Missões jesuítico-guaranis?
}

\author{
Patrimonio inmaterial en el Camino de las Misiones: ¿créditos \\ conmemorativos o narrativos coloniales sobre las Misiones Jesuítico- \\ guaranies?
}

\section{Intangible heritage in the Paths of Missions: memorial appropriations or colonial narratives about the Jesuit-Guaranis Missions?}

\author{
Ingrid Bomfim Gonçalves ${ }^{1}$
}

Larissa Conceição dos Santos²

\begin{abstract}
Resumo
O estudo investiga o patrimônio cultural missioneiro e as modalidades de apropriação e exploração turística realizadas pela operadora "Caminho das Missões", que ofertava, inicialmente, roteiros de peregrinação pela região da Missões no Rio Grande do Sul, mas que desde 2012 passa a incluir um percurso internacional englobando os territórios argentinos e paraguaios. Nesse sentido, a pesquisa analisa a oferta turística comercializada pelo "Caminho das Missões", tendo o patrimônio cultural missioneiro como principal atrativo, bem como reflete-se sobre a importância da memória e das narrativas propagadas ao longo do percurso, como elementos centrais na constituição imaterial desse patrimônio e de que maneira são retratados os seus personagens fundamentais, jesuítas e guaranis. Para isso, realiza-se uma pesquisa exploratória apoiada por metodologia bibliográfica e documental, além de entrevistas abertas com representantes da operadora turística, e pesquisa etnometodológica compreendendo pesquisa de campo, registro fotográfico e registro textual em diário de campo, realizadas em 2019. Como principais observações, identificou-se que a memória e os relatos dos povos indígenas são sistematicamente silenciados em parte do roteiro realizado em solo brasileiro, sinalizando a adoção de uma narrativa colonial hegemônica, que destaca e enaltece os jesuítas e retraça o seu percurso e suas práticas, em detrimento do legado guarani.
\end{abstract}

Palavras-Chave: Guarani; Missões; Narrativa; Patrimônio cultural; Povos indígenas.

\section{Resumen}

El estudio investiga el patrimonio cultural misionero y las modalidades de apropiación y exploración turística llevada a cabo por el operador "Caminho das Missões", que inicialmente ofrecía itinerarios de peregrinación por la región de Misiones en Rio Grande do Sul, pero que desde 2012 ha incluido una ruta internacional que abarca los territorios argentino y paraguayo. En este sentido, la investigación analiza la oferta turística comercializada por el " Caminho das Missões ", con el patrimonio cultural misionero como principal atractivo, así como reflexiona sobre la importancia de la memoria y las narrativas propagadas a lo largo de la ruta, como elementos centrales en la constitución intangible de este patrimonio y cómo se retratan sus personajes fundamentales, jesuitas y guaraníes. Para ello, se lleva a cabo una investigación exploratoria apoyada por la metodología bibliográfica y documental, además de entrevistas abiertas con representantes de la operadora turística, y la

\footnotetext{
${ }^{1}$ Mestranda em Comunicação e Indústria Criativa; Universidade Federal do Pampa; São Borja, Rio Grande do Sul, Brasil; ingridbgoncal@gmail.com.

2 Professora Adjunta; Universidade Federal do Pampa; São Borja, Rio Grande do Sul, Brasil; larissasantos@unipampa.edu.br.
} 
investigación etnometodológica que comprende la investigación de campo, el registro fotográfico y el registro textual en el diario de campo, llevado a cabo en 2019. Como observaciones principales, se identificó que la memoria y los relatos de los pueblos indígenas son sistemáticamente silenciados en parte del trayecto realizado en suelo brasileño, lo que indica la adopción de una narrativa hegemónica colonial, que destaca y alaba a los jesuitas y reconstituye su itinerario y sus prácticas, en detrimento del legado guaraní.

Palabras claves: Guaraní; Misiones; Narrativa; Patrimonio cultural; Pueblos indígenas.

\begin{abstract}
The study investigates the missionary cultural heritage and the modalities of appropriation and tourist exploration carried out by the operator "Caminho das Missões", which initially offered pilgrimage itineraries through the Missions region in Rio Grande do Sul, but which since 2012 has included an international route encompassing the Argentine and Paraguayan territories. In this sense, the research analyzes the tourist offer commercialized by the "Caminho das Missões", with the missionary cultural heritage as the main attraction, as well as reflects on the importance of memory and narratives propagated along the route, as central elements in the intangible constitution of this heritage and how its fundamental characters, Jesuits and Guarani are portrayed. For this, an exploratory research is carried out supported by bibliographic and documentary methodology, in addition to open interviews with representatives of the tour operator, and ethnometodological research comprising field research, photographic record and textual record in field diary, carried out in 2019. As main observations, it was identified that the memory and reports of indigenous peoples are systematically silenced in part of the itinerary carried out on Brazilian soil, signaling the adoption of a hegemonic colonial narrative, which highlights and praises the Jesuits and retraces their path and practices, to the detriment of the Guarani legacy.
\end{abstract}

Keywords: Guarani; Missions; Narrative; Cultural heritage; Indian people.

\title{
1. Introdução
}

O patrimônio cultural pode ser de natureza material e imaterial. Segundo o Instituto do Patrimônio Histórico e Artístico Nacional (IPHAN), os bens tombados de natureza material podem ser imóveis como as "cidades históricas, sítios arqueológicos e paisagísticos e bens individuais; ou móveis, como coleções arqueológicas, acervos museológicos, documentais, bibliográficos, arquivísticos, videográficos, fotográficos e cinematográficos”. Já o patrimônio imaterial segundo o IPHAN, está relacionado "às práticas e domínios da vida social que se manifestam em saberes, ofícios e modos de fazer; celebrações; formas de expressão cênicas, plásticas, musicais ou lúdicas; e nos lugares".

A região das Missões jesuítico-guaranis, cujo território ultrapassa as fronteiras brasileiras e se estende até o Paraguai, passando ainda por terras argentinas, é composta por diferentes sítios arqueológicos tombados pela UNESCO como patrimônios culturais da Humanidade, não apenas por sua riqueza material, mas igualmente por seu legado históricocultural.

Nesse contexto, diferentes iniciativas voltadas à promoção turística foram desenvolvidas nessas regiões, que fomentam a visitação e o (re)conhecimento do patrimônio cultural missioneiro, como, por exemplo: o Circuito Internacional das Missões Jesuíticas, um dos mais importantes produtos turísticos do Mercosul e reconhecido pela UNESCO como um 
dos principais roteiros históricos internacionais mundiais (NOGUEIRA; BURKHARD, 2008), compreendendo territórios brasileiros, argentinos, paraguaios e uruguaios; no Brasil temos ainda a criação da "Rota da Missões", produto turístico incentivado pelo SEBRAE-RS em 2003 e, posteriormente, integrado ao mapa político-geográfico do turismo no Rio Grande do Sul (SCHERER et al., 2017); e, finalmente, o roteiro turístico "Caminho das Missões", comercializado pela Operadora turística homônima.

$\mathrm{O}$ artigo busca analisar de que maneira o patrimônio cultural missioneiro é explorado, comercialmente, através do roteiro turístico-cultural "Caminho das Missões", lançado oficialmente em 2003 e, desde 2019, com a oferta internacional, para além da fronteira sul brasileira, nos territórios argentinos e paraguaios.

De maneira geral, busca-se observar de que maneira o patrimônio cultural (imaterial) missioneiro é explorado turisticamente por meio da comercialização de roteiros de peregrinação ofertados pela Operadora de Turismo Caminho das Missões, que oferecem, desde 2003, várias opções de percursos pelos Sítios Arqueológicos e reduções jesuíticoguarani brasileiras, argentinas e paraguaias.

Adicionalmente, observa-se como o patrimônio imaterial e, especialmente, a memória dos povos originários é sistematicamente silenciada em parte do roteiro realizado em solo brasileiro, sinalizando a adoção de uma narrativa colonial hegemônica que destaca e enaltece os jesuítas e retraça o seu percurso e suas práticas, em detrimento do legado guarani.

Para tal, realiza-se uma pesquisa exploratória (RAUPP; BEUREN, 2009) apoiada por metodologia bibliográfica e documental (MARCONI; LAKATOS, 2007), esta última com foco nos documentos oficiais publicizados pela operadora turística, além de entrevistas abertas com representantes da operadora, e pesquisa etnometodológica (COULON, 1995) compreendendo pesquisa de campo (GODOY, 1995), registro fotográfico e registro textual em diário de campo (BRAZÃO, 2007), realizadas em 2019.

Como resultante, espera-se que o trabalho contribua ao conhecimento e reconhecimento da rota "Caminho das Missões" como patrimônio cultural imaterial missioneiro, além de refletir sobre as apropriações memoriais em torno dos personagens que compõem a história das missões - especialmente jesuítas e guaranis -, o papel que ocupam nas narrativas oficiais propagadas pela operadora turística ao longo do percurso de peregrinação e, finalmente, as disputas de sentido nesse relato legitimante, que, a partir das análises empreendidas, apenas reforçam a versão colonizadora tradicionalmente reproduzida nos manuais escolares. 


\section{As Missões jesuítico-guarani: Entre Brasil, Argentina e Paraguai}

A criação das Missões jesuítico-guarani foram parte do projeto de tomada da América, elaborado pelas coroas ibéricas durante os séculos de XVI, XVII e XVIII (VALENZUELA, 2013). Nesse sentido, a colonização dos espanhóis na América buscou a catequização e civilização dos povos indígenas que habitavam estes territórios.

Conforme apontamentos de Pinto (2011), o processo de fundação das Missões ocorreu em dois ciclos que contribuíram para a constituição de trinta povoados missioneiros. No primeiro ciclo foram fundadas reduções no Paraguai, Argentina, Uruguai e Brasil.

No território pertencente ao Paraguai permaneciam os índios Tupi-guarani, que migraram em direção ao sul - entorno do Rio Uruguai -, em busca da 'terra sem mal"' (CUSTÓDIO, 2007, p. 65). A “terra sem mal” de acordo com Custódio (2007, p. 65 apud MÉLIA, 1988), é “ante todo la tierra buena, fácil para ser cultivada, productiva, suficiente y amena, tranquila y apacible, donde los Guaraní puedan vivir em plenitude su modo de ser auténtico".

Partindo desse pressuposto, foi a partir da busca pela "terra sem mal" que consolidouse o segundo ciclo das Missões na banda oriental do Rio Uruguai, conhecidos atualmente como os "Sete Povos das Missões", pertencentes ao território do Rio Grande do Sul.

De acordo com Pinto (2011) às cidades do Rio Grande do Sul que fazem parte dos povoados missioneiros são: São Francisco de Borja (1682), São Nicolau (1687), São Luiz Gonzaga (1687), São Miguel Arcanjo (1687), São Lourenço Mártir (1690), São João Batista (1697) e Santo Ângelo Custódio (1706).

No território Argentino fazem parte das Missões as cidades de: Nuestra Señora de Loreto (1610), Concepción de la Sierra (1619), Corpus Christi (1622), Nuestra Señora de los Santos Reyes Magos de Yapeyú (1627), Santa María Mayor (1626), San Javier (1629), Nuestra Señora de Asunción de La Cruz de Mbororé (1630), San Carlos (1631), Santo Tomé (1632), San Ignácio Miní (1632), Nuestra Señora de Santa Ana (1633), Candelaria (1637), San José de Ita-cua (1638), Santos Apósteles Pedro y Pablo (1638) e Mártires (1639).

E no Paraguai: San Ignácio Guazú (1609), Encarnación de Itapúa (1615), Santa Maria de Fe (1647), San Cosme Y Damián (1632), Santiago Apóstol (1651), Jesús de Tavarengue (1685), Santa Rosa de Lima (1698) e La Santísima Trinidad de Paraná (1706).

A distribuição geográfica das referidas reduções jesuíticas, entre os três países citados, pode ser observado na Figura 1- Reduções jesuíticas na Argentina, Brasil e Paraguai. 


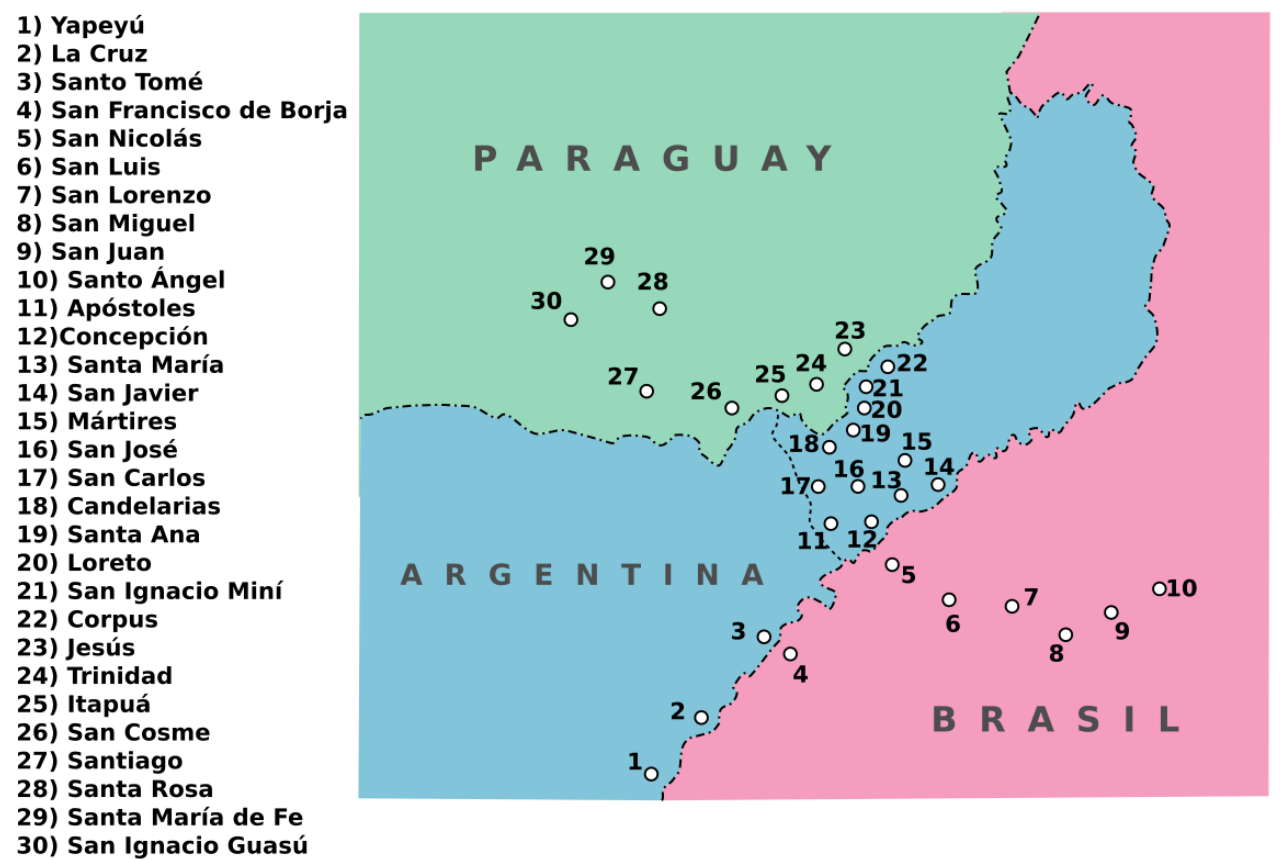

Figura 1 - Reduções jesuíticas na Argentina, Brasil e Paraguai Fonte: https://es.wikipedia.org/wiki/Archivo:Reducciones.svg

De acordo com Stefano (1997, p. 188), das Reduções jesuítico-guarani supracitadas, apenas dezoito ainda contam com Sítios históricos, sendo sete na Argentina (San Ignácio Miní, Santa Ana, Loreto, Santa María la Mayor, Yapeyú, San Carlos, Apóstoles); quatro no Brasil (São Nicolau, São Miguel, São Lourenço e São João) e sete no Paraguai (Trinidad, Jesús, San Ignácio, Santa Maria de Fe, San Cosme y Damián, San Santiago e Santa Rosa).

Dentro dessa perspectiva, pode-se visualizar os Sítios Arqueológicos como parte do Patrimônio Cultural missioneiro, como, por exemplo, o Sítio Arqueológico de São Miguel Arcanjo, o qual também é reconhecido como Patrimônio da Humanidade e tombado como Patrimônio Cultural Imaterial "Tava", lugar de referência para o povo guarani e o Sítio Arqueológico de São João Batista, que é tombado como Patrimônio Histórico e Artístico Nacional.

Além disso, quando é feita referência a presença missioneira e suas utilizações, sejam elas turísticas ou patrimoniais, é importante salientar que isso envolve um conjunto de relações plurais entre o passado e o presente. Brum (2006, p. 31) evidencia que acionar o passado missioneiro "remete à questão das suas múltiplas utilizações sociais e outros suportes de memória menos valorizados, mas fundamentais para se entender os imaginários decorrentes dele".

Nesse sentido, entende-se que o patrimônio cultural missioneiro também envolve uma série de questões simbólicas e intangíveis, que constituem o patrimônio imaterial, o qual 
segundo Vianna e Teixeira (2016, p. 127) pode ser entendido como "um sistema de práticas tradicionais reconhecidas e transmitidas de geração em geração, ao longo de um tempo, caracterizando identidades coletivas".

Pinto (2011, p. 94) ainda salienta que:

\begin{abstract}
No que se refere ao patrimônio imaterial missioneiro, as festas e celebrações destacam-se pela quantidade e diversidade de ocorrências, como: gauchescas; religiosas; étnicas; naturais; agropecuárias; artísticas; culturais; gastronômicas; natalinas. Os principais rituais são visualizados na comunidade Mbya-Guarani de São Miguel das Missões. Entre os espaços de práticas culturais coletivas, salientamse os grupos de dança, música, orquestras (germânicas; polonesas; Mbyá-Guarani, italianas, afrodescendentes), teatro, pintura, artes plásticas e visuais missioneiras. Já as formas de expressão identificadas nas Missões, como literatura, musicalidade, artes cênicas, artes plásticas, voltam-se para a essencialização e estereotipia da cultura missioneira.
\end{abstract}

A estereotipia da cultura missioneira, como descreve Pinto (2011), envolve uma gama de questões que constantemente entram em cena com o discurso do tipo social do gaúcho missioneiro. Alguns elementos são fortemente associados como constituintes da construção da identidade missioneira, como, por exemplo, a da figura mítica de Sepé Tiaraju e a exaltação de lendas e contos.

Conforme salienta Pinto (2011), em virtude da grande miscigenação étnica da região das Missões, ainda ocorrem outros tipos de expressão no que se refere à cultura, isto é, manifestações da cultura pampeana, típica da região do pampa; manifestações culturais dos descendentes europeus; guaranis e afrodescendentes.

\title{
3. "Caminho das Missões": monetização da rota turística para além das fronteiras
}

O "Caminho das Missões" é um roteiro turístico-cultural criado por quatro sócios da Operadora de Turismo Caminho das Missões, em 1999. Este roteiro tem como objetivo conectar os caminhos jesuítico-guarani originais, por meio de trilhas antigas, que eram percorridas para locomoção entre as reduções.

A rota turística de peregrinação pela região conhecida como os "Sete Povos da Missões", no Rio Grande do Sul, ofertada e comercializada pela operadora turística "Caminho das Missões", pode ser observada na Figura 2 - Mapa do "Caminho das Missões". 


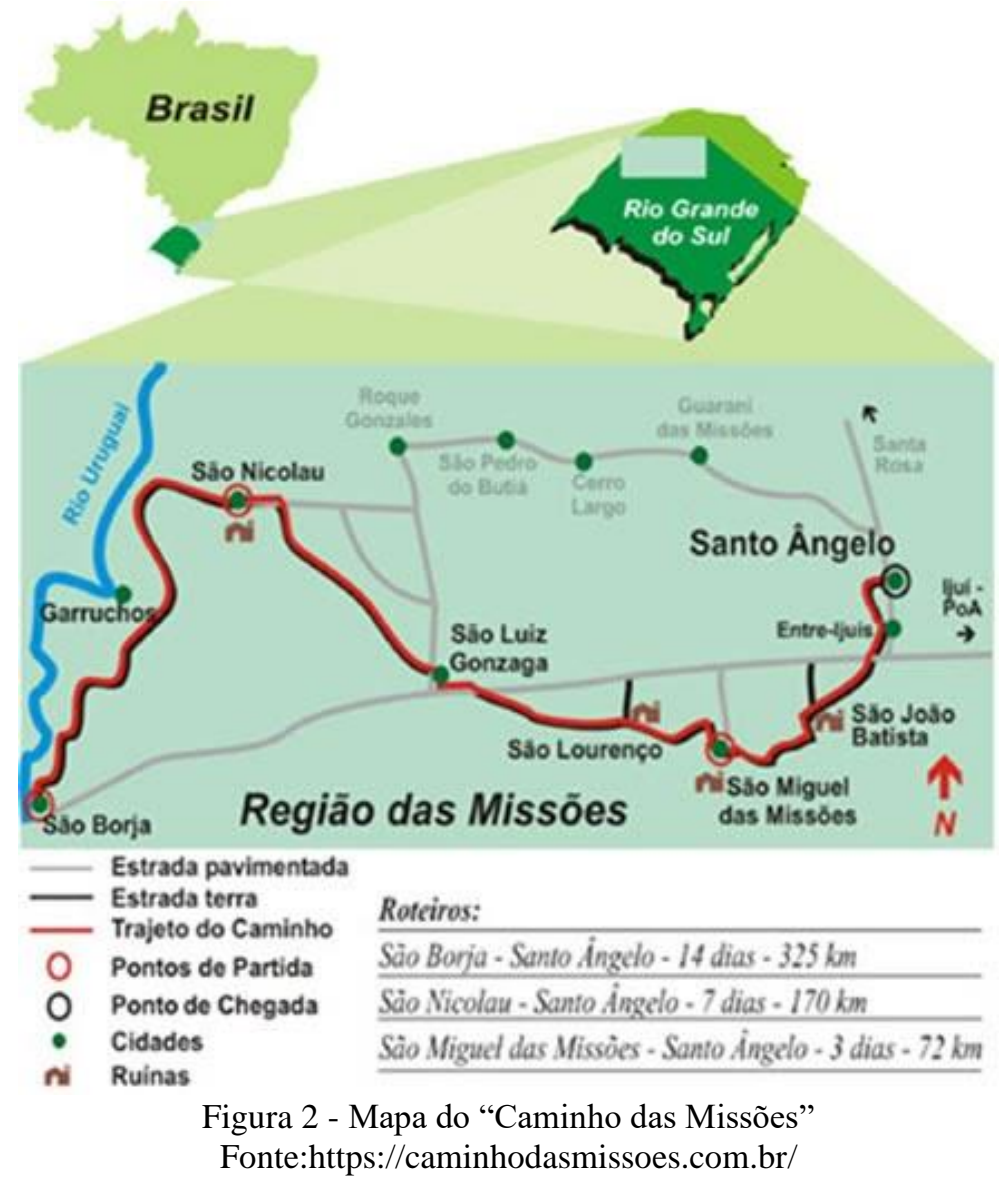

A Operadora de Turismo Caminho da Missões é quem mantém o monopólio do roteiro, comercializando caminhadas em grupo ou individuais, cicloturismo, e trilhas que abrangem a região das Missões e estendem-se a diversos países da América do Sul.

A Operadora iniciou o empreendimento comercializando apenas produtos que incluíam as Missões do Rio Grande do Sul, com um trajeto que ia de São Miguel das Missões/RS a Santo Ângelo/RS, envolvendo cerca de 72 quilômetros de caminhada . Nos ano seguintes foi incluído o trajeto de São Nicolau/RS a Santo Ângelo/RS, e após sucessivamente introduziram-se mais municípios no caminho até chegar no trajeto de 14 dias que vai da cidade de São Borja/RS a Santo Ângelo/RS, com aproximadamente 325 quilômetros de jornada, o qual abrange os Sete Povos das Missões.

Em 2012 foi realizada uma caminhada experimental para dar início a internacionalização do caminho, incluindo a Argentina e o Paraguai no roteiro, e no ano de 2019 realizou-se a caminhada oficial pelos trinta povos das Missões, buscando, dessa forma, promover a união entre os povos missioneiros e também fomentar o turismo no Mercosul, conforme pode ser observado no material de divulgação publicizado pela operadora turística e apresentado na Figura 3 - Folder de divulgação da caminhada internacional. 


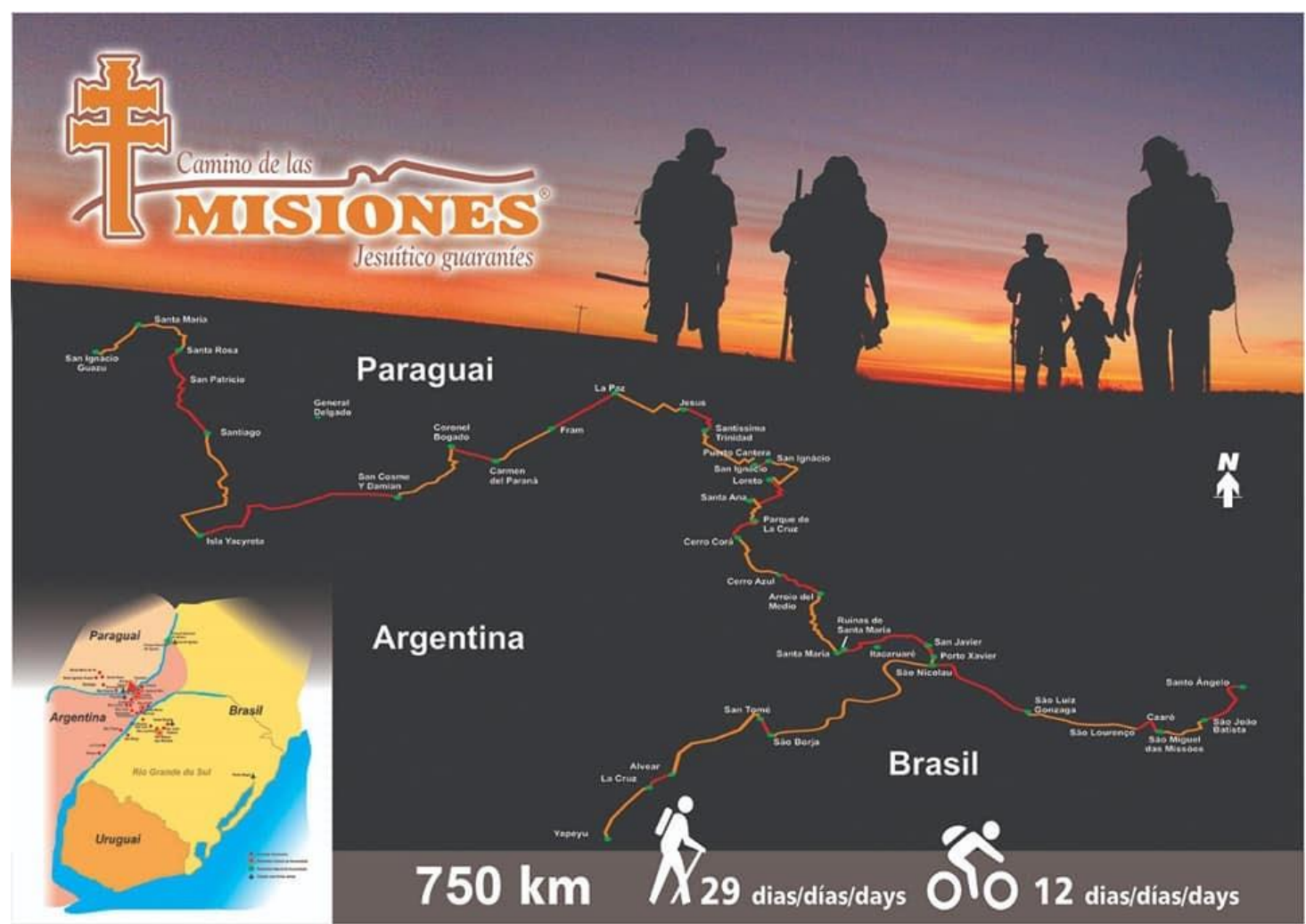

Figura 2 - Folder de divulgação da caminhada internacional

Fonte: https://www.facebook.com/caminhodasmissoes/photos/2324787184304259

Conforme analisam Nogueira e Buckhard (2008), o Circuito Internacional das Missões Jesuíticas já existe como produto turístico internacional desde 1995 e fora um esforço de aproximar os países que detêm esse rico patrimônio cultural, material e imaterial, que são as reduções jesuíticas-guaranis. Assim, a iniciativa foi fomentada pelo Sub-grupo 13, órgão executivo do Mercosul, em um esforço de integração regional entre o Brasil, a Argentina, o Paraguai e o Uruguai, apesar de este último, pela distância geográfica da Colônia de Sacramento das demais reduções jesuíticas, acabar sendo o menos visitado pelos viajantes que realizam o circuito internacional missioneiro (NOGUEIRA; BURKHARD, 2008). Deduz-se daí que a opção da operadora turística Caminho da Missões pela não inclusão do sítio uruguaio em sua rota se deva pelas mesmas razões.

Pinto (2011, p. 83), salienta que este trajeto "materializa e essencializa a cultura missioneira através de uma narrativa marcada pela alteridade”, isto é, dispõe de um grande potencial turístico e representatividade da herança cultural dos povos que habitam a região.

Nesta conjuntura, percebe-se que o caminho movimenta a economia local no meio urbano e rural, já que as caminhadas são realizadas no interior dos municípios. E 
consequentemente também impacta na economia dos indígenas, os quais têm a oportunidade de comercializar seus artesanatos e mostrar a sua cultura, que é eventualmente lembrada.

Alves (2007) salienta que o "Caminho das Missões" revelou-se como uma nova oportunidade de geração de renda para os vários municípios que integram o projeto, entretanto quem mantém o monopólio é a Operadora de Turismo já citada anteriormente, a qual é privada. O autor afirma que "o caráter incipiente, a pequena demanda e os poucos recursos investidos na divulgação e infraestrutura contribuem para que não tenha se concretizado ainda como um setor de maior renda e para um número maior de pessoas" (2007, p. 11) .

Acredita-se que em decorrência da ampliação do roteiro para além das fronteiras, incluindo a Argentina e o Paraguai, a exploração turística da região passe a se expandir, podendo ocasionar em um desenvolvimento econômico para a região. Todavia, devido ao contexto atual de pandemia do coronavírus, ainda não se sabe ao certo como essas questões serão abordadas pelas autoridades internacionais.

O que se sabe é que faz-se necessário perceber que o patrimônio cultural coloca em circulação bens culturais de extrema importância no mercado da intangibilidade. Por isso, julga-se pertinente que os órgãos públicos prestem apoio ao roteiro turístico-cultural, e, mais do que isso, no processo de valorização deste patrimônio intangível; em iniciativas restaurativas; na valorização da mídia em torna das questões comunicacionais do patrimônio; e na valorização do patrimônio como herança histórica.

\section{Narrativas, memórias e esquecimentos na rota Caminho das Missões}

Retomando o pensamento de Gonçalves (1996; 2012) sobre o papel da perda e do esquecimento (destruição ou desaparecimento) na conformação do patrimônio cultural, MELO et al. (2015) destacam o fenômeno da objetificação cultural como a busca por tangibilizar o intangível, fato que ocorre porque "estaríamos imbuídos por um desejo de salvaguarda dos bens, mesmo sendo estes, imateriais. As narrativas estão contempladas nessa reflexão, pois são da ordem oral, uma construção ficcional, que de alguma maneira, procuramos tornar concretas (MELO; LUNA; RIBEIRO, 2015, p. 8)”.

Conforme assinala Bruner (2006), as narrativas servem à compreensão da realidade e também como forma de apreensão da cultura, esta entendida como um sistema de significações que derivam da apropriação que realizamos do conjunto de narrativas que compõem a cultura de um povo ou civilização. Por isso é tão importante observarmos a 
circulação de tais narrativas na sociedade, o surgimento de narrativas dominantes ou legitimantes, conforme destaca Lyotard (1969), que buscam apresentar uma dada visão do mundo e da verdade a partir de óticas muitas vezes particulares e excludentes.

Nesse sentido, entende-se as narrativas como elementos fundamentais na composição do patrimônio cultural imaterial, que expressam e (re)traçam a memória das expressões culturais, dos ritos, mitos e práticas que já não podemos mais observar, mas que podem ser ressignificados na atualidade a partir dos relatos preservados e passados de uma geração a outra.

No caso aqui observado, o patrimônio imaterial da região das Missões compreende, sobremaneira, a memória dos povos indígenas, originários, constituintes e representativos da cultura missioneira. O que se observa, no entanto, ao realizar um percurso exploratório pela rota "Caminho da Missões" no Rio Grande do Sul, é que a narrativa desenvolvida colabora para a exaltação do papel dos jesuítas no processo de conformação das reduções jesuíticas e para o desenvolvimento das cidades que constituem os "Sete Povos das Missões", em detrimento da memória indígena e dos relatos desses personagens fundamentais.

A partir de um percurso de 3 dias, realizado em julho de 2019, no qual realizou-se uma pesquisa etnometodológica, apoiada por pesquisa de campo e registro em diário de campo, foi possível observar, entre outros aspectos, a dimensão narrativa e os usos e apropriações da memória como elementos centrais na formação desse patrimônio cultural imaterial missioneiro, explorado, de forma privilegiada, pela Operadora de Turismo Caminho das Missões. Nesse sentido, foi necessário adquirir um pacote específico, junto à referida Operadora de turismo, para a realização da rota de peregrinação, a qual incluía no trajeto a passagem pelas cidades de São Miguel das Missões, Entre Ijuís e Santo Ângelo, contando com acompanhamento de uma guia turística durante todo o percurso.

Como principais observações, destaca-se a adoção e o reforço à narrativa colonial hegemônica, dos missioneiros jesuítas, propagada não apenas pelas escolhas estratégicas deste percurso turístico - retraçar o caminho dos jesuítas pela região das Missões - mas, também, pelos "relatos de acompanhamento" contados pelos guias e mediadores (famílias que recepcionam os visitantes em certos pontos do caminho) ao longo do trajeto. A narrativa dos povos indígenas, de seus cultos, ritos e de seus feitos, dá lugar ao relato do colonizador jesuíta como protagonista (ou mesmo herói) dessa história.

Entende-se, conforme afirma Lyotard (1969), que a disseminação de tais relatos legitimantes, que buscam assumir o lugar de verdades absolutas, colaboram à romantização da história da Missões por meio de uma narrativa civilizatória e desenvolvimentista, em que os 
jesuítas ocupam o papel central, como beneméritos pacificadores dos povos selvagens que aqui habitavam, porém, omitindo as agressões, os abusos e a exploração a que estes grupos foram submetidos.

O conhecimento e reconhecimento desses povos passa pela transmissão de suas histórias de geração a geração, pela visibilidade de seus relatos e pela afirmação de seu protagonismo e ancestralidade no território que hoje é reconhecido como missioneiro. Assim, tais narrativas constituem o patrimônio imaterial das Missões e, portanto, devem colaborar para relatar de maneira fidedigna os fatos e acontecimentos representativos do período missioneiro, assumindo os abusos e violações sofridos pelos povos detentores destas terras e que, além de terem sidos saqueados e oprimidos, são omitidos ou silenciados nas narrativas "oficiais", como é o caso dos relatos aqui observados na rota brasileira do "Caminho das Missões".

Partindo desse pressuposto, compreende-se que o pesquisador tem um papel de extrema importância, no que diz respeito a publicização dessas questões. Dezordi (2016, p. 65), aponta que "trazer ao público elementos que compõem as histórias das comunidades indígenas é uma das formas de mostrar a necessidade de mudança na visão que a sociedade nacional, de um modo geral, ainda perpetua". Essa postura de "desvalorizar" e "desprezar" a cultura indigena, empregada no cenário nacional, faz parte de um processo colonizador com cerca de quinhentos anos, o que esclarece ainda mais a falta de democracia racial, étnica, cultural e política no contexto em que vivemos.

A tribo de indígenas que habitam na região das Missões, no Noroeste do estado do Rio Grande do Sul, são os Mbyá que "pertencem à família linguística Tupi-Guarani, falantes da língua Guarani e estão presentes, sobretudo nos estados litorâneos brasileiros desde o Espírito Santo até o Rio Grande do Sul” (DEZORDI, 2016, p. 21). Os Mbyá que vivem no RS habitam dois municípios, sendo estes, respectivamente, Santo Ângelo e São Miguel das Missões. Todavia, é notório que grande parte dos Mbyá se concentram no Sítio Arqueológico de São Miguel, onde comercializam seus artesanatos para os visitantes do local.

A partir do silenciamento da narrativa indigena no "Caminho das Missões" e levando em consideração o papel de coadjuvantes que eles assumem diante desse cenário, Dezordi (2016) aponta que os Mbyá desejam que a sua cultura seja valorizada, e além disso, que também as questões do ponto de vista legal sejam levadas em consideração, isto é, dos direitos indígenas, da proteção do seu espaço para viver e reconhecimento de seu lugar na sociedade. 
Em virtude da Pandemia do SarsCov2, não foi possível realizar o percurso internacional ofertado pela operadora turística, porém, os registros realizados a partir da experiências brasileira nas Missões nos apontam indícios e dão o tom a respeito da narrativa colonial legitimante adotada pelo "Caminho das Missões" e que, possivelmente, será aquela propagada e reproduzida pelos guias ao longo do trajeto pelas ruínas argentinas e paraguaias.

\section{Conclusões}

A partir do estudo desenvolvido, foi possível observar que a operadora turística "Caminho das Missões" além de ser detentora do monopólio e explorar com exclusividade a rota de peregrinação que leva o seu nome, também assume o controle da narrativa oficial propagada ao longo desse percurso e, embora não tenhamos acesso direto aos relatos dos povos indígenas, isso não significa que sua memória tenha sido esquecida, ela apenas não é convoca a integrar a versão oficial contada nesse "caminho missioneiro". Como resultado, as terras, a história e a cultura dos povos originários torna-se objeto de consumo turístico, sem que tais grupos tenham a devida valorização - moral ou monetária- ou que suas lutas e suas perdas sejam assumidas e reconhecidas, por meio da narrativa que acompanha e guia os peregrinos-visitantes.

É oportuno pensar que o investimento turístico pode auxiliar e dar visibilidade ao patrimônio cultural existente nas Missões, entretanto, percebe-se que o recurso financeiro arrecadado não reverte, proporcionalmente, em investimentos para a conservação, valorização ou melhoria deste patrimônio, ou seja, nota-se que muito se extrai e pouco se investe na região, o que deveria acarretar em um desenvolvimento local, acaba sendo apenas exploração turística.

Por outro lado, acredita-se que o turismo seja, por vezes, uma das únicas rendas que os indígenas possuem, isto é, com as vendas de seus trabalhos artesanais para os turistas e peregrinos do "Caminho das Missões". E agora, com a internacionalização do roteiro, os indígenas da Argentina e Paraguai também poderão investir em trabalhos manuais para comercialização.

Ainda dentro da perspectiva indígena, observa-se uma relação complexa que narra o que conveniou-se denominar de "aculturação" dos povos indígenas, hoje entendido como um processo de interculturalidade (REPETTO, 2019), que coloca as relações sociais no centro das discussões a respeito da cultura dos grupos originários. Conforme observado a partir do percurso pela rota brasileira do "Caminho das Missões", a cultura indígena, embora 
mencionada ao longo do trajeto, não ocupa um lugar de destaque na narrativa missioneira. $\mathrm{O}$ que se observa é uma inversão de prioridades e de papéis, que exalta os grupos opressores jesuítas - e deixa em segundo plano a figura dos oprimidos - povos indígenas - colaborando à legitimação de um relato colonialista e eurocentrista, propagada em território tupiniquim.

O caso analisado, da rota turística "Caminho da Missões", revela, por uma lado, aspectos interessantes, relativos à valorização do Patrimônio cultural missioneira em uma perspectiva transfronteiriça, mas por outro, escancara a face muitas vezes perversa da exploração turística, que, nesse caso, é observada pela objetificação dos povos indígenas, que assumem um papel coadjuvante no relato oficial da operadora turística.

Entende-se que os povos originários e, no contexto missioneiro especialmente os guaranis, são os atores principais desse contexto histórico, tendo resistido ao período reducional, garantindo a sua permanência até a atualidade (GONÇALVES; SANTOS, 2020) e que, portanto, devem ter o seu protagonismo reconhecido, seja pela legitimidade destes grupos pioneiros e originários das terras e sítios hoje tombados como Patrimônio Mundial da Humanidade pela UNESCO, seja pelos abusos, violações, e a exploração a que foram submetidos, tendo lutado e resistido para garantir a conservação da memória da sua comunidade, de suas práticas e da cultura invisível (SOUZA, 2010) que compõe a imaterialidade do patrimônio missioneiro.

\section{Referências}

ALVES, C. A. S. O Caminho das Missões e seus peregrinos: nova modalidade de produto turístico da região das Missões. Dissertação (Mestrado) - Universidade Federal do Rio Grande do Sul. Programa de Pós-Graduação em Ciências Sociais. Porto Alegre, 2007. Disponível em: http://tede2.pucrs.br/tede2/handle/tede/4751. Acesso em: Nov. 2020.

BRAZÃO, P. O diário do diário etnográfico electrónico. Assa editores: Porto, 2007.

BRUM, C. K. Missões: reflexões e questionamentos. Editora e Gráfica Caixas. Santa Maria, 2016.

BRUNER, J. S. La culture, l'esprit, les récits. Enfance, 2006, vol. 58, n.2, p. 118-125. Disponível em: https://www.cairn.info/revue-enfance1-2006-2-page-118.htm Acesso em: 14 dez. 2020.

COULON, A. L'ethnométhodologie. Paris: PUF, 1987.

CUSTÓDIO, L. A. B. Missões: patrimônio e território. Porto Alegre: Ed. UFRGS, 2007. 
DEZORDI, E. Aqui plantamos uma semente: o surgimento da Tekoa Pyaú em uma comunidade Mbyá estabelecida no município de Santo Ângelo, Rio Grande do Sul. Dissertação (Mestrado - Área de concentração em Antropologia Social e Cultural) Universidade Federal de Pelotas. Programa de Pós-graduação em Antropologia. Pelotas, 2016. Disponível em: http://bdtd.ibict.br/vufind/Record/UFPL_2fdd919ff783613b bb83ffd5bd1f99eb.

GODOY, A. S. Introdução à Pesquisa Qualitativa e suas possibilidades. São Paulo: Revista de Administração de Empresas, v. 35, n. 2, p. 57-63, 1995.

GONÇALVES, J. R. S. A retórica da perda: os discursos do patrimônio cultural no Brasil. Rio de Janeiro: Editora UFRJ, 1996.

. As transformações do patrimônio: da retórica da perda à reconstrução permanente. In: TAMASO, I. M.; LIMA FILHO, M. F. (Orgs.). Antropologia e Patrimônio Cultural: trajetórias e conceitos. Brasília: Associação Brasileira de Antropologia, 2012. p. 59-73.

GONÇALVES, I. B.; SANTOS, L. C. Memórias (re)configuradas e disputas de sentidos nas narrativas do "Caminho das Missões". In: MAIA, M.; PASSOS, M. Y. (Orgs.) Narrativas midiáticas contemporâneas: epistemologias dissidentes. Santa Cruz do Sul: Catarse, 2020. p. 31-46.

IPHAN. A atuação do IPHAN nas Missões. Tava Miri São Miguel Arcanjo, Sagrada Família Aldeia de Pedra: os Mbyá-Guarani nas Missões. Porto Alegre: IPHAN, 2007.

LYOTARD, J.F. La condition postmoderne. Paris: Minuit, 1979.

MARCONI, M.; LAKATOS, E. M. Fundamentos de Metodologia científica. 5.ed. São Paulo: Atlas, 2003.

MELO, K.C. B. S.; LUNA, S.; RIBEIRO, L. B. Patrimônio: uma jornada de coleção e memória In: Anais...Congresso Internacional Interdisciplinar em Ciências e Humanidades CONINTER 4, 2015. Foz do Iguaçu, UNIOESTE, 8 a 11 de dezembro de 2015.

NOGUEIRA, C. D.; BURKHARD, D. Políticas públicas de turismo para o desenvolvimento local/regional das missões jesuíticas-guarani. Revista eletrônica de turismo cultural, v. 2, n. 2 , 2008. Disponível em:

http://www.eca.usp.br/TURISMOCULTURAL/Retc04_arquivos/Carmen_Missoes.pdf

Acesso em: 14 dez. 2020.

PINTO, M. A construção da Identidade Missioneira no Rio Grande do Sul e as Políticas Culturais no Sul do Brasil. Dissertação (Mestrado - Área de concentração em Planejamento Urbano e Regional) - Universidade de Santa Cruz do Sul. Programa de Pós-Graduação em Desenvolvimento Regional. Santa Cruz do Sul, 2011. Disponível em: https://repositorio.unisc.br/jspui/handle/11624/301.

RAUPP, F. M; BEUREN, I. M. (org.). Metodologia da Pesquisa Aplicável às Ciências. São Paulo: Atlas, p. 76-97, 2009. 
REPETTO, M. O Conceito de Interculturalidade: trajetórias e conflitos desde América Latina. Textos e Debates, v. 2, n. 33, 2019. Disponível em:

https://revista.ufrr.br/textosedebates/article/view/5986 Acesso em: 14 dez. 2020.

SCHERER, L. et al. Descentralização de recursos financeiros públicos federais destinados ao turismo para municípios integrantes da Rota Missões-RS: uma análise sobre desenvolvimento e turismo. Revista Gesto, v. 5, n. 2, p. 19-36, 2017. Disponível em:

https://core.ac.uk/download/pdf/322642076.pdf Acesso em: 13 dez.2020.

SOUZA, M. S. C. A cultura invisível: conhecimento indígena e patrimônio imaterial. Anuário Antropológico, n. I, p. 149-174, 2010. Disponível em: https://journals.openedition.org/aa/813 Acesso em: 14 dez. 2020.

STEFANO, R. D. The integrated preservation of the Jesuit Missions. In: UNESCO; ICOMOS (Orgs). The Jesuit missions of the Guarani. Verona: Commercial Bureau, 1997, p. 186-199.

VALENZUELA, T. S. Jogos e ensino de História: uma proposta de reconhecimento do patrimônio cultural dos 7 povos das missões. Dissertação (Mestrado) - Universidade Federal de Santa Maria. Programa de Pós- Graduação Profissional em Patrimônio Cultural. Santa Maria, 2013.

VIANNA, L. C.R; TEIXEIRA, J. G. L.C. Patrimônio imaterial, performance e identidade. Revista Concinnitas, v. 1, n. 12, p. 121-129, 2016. Disponível em: https://www.epublicacoes.uerj.br/index.php/concinnitas/article/download/22822/16282 Acesso em: $15 \mathrm{dez}$. 2020.

\section{Sites consultados:}

CAMINHO DAS MISSÕES. Roteiros turísticos. Disponível em: http://www.caminhodasmissoes.com.br/Acesso em: 13 novembro 2020.

CAMINHO DAS MISSÕES. Facebook. Fotos. Disponível em: https://www.facebook.com/caminhodasmissoes/Acesso em: 10 novembro 2020.

ROTA MISSÕES. Secretaria de Desenvolvimento econômico e turismo. Disponível em: https://www.turismo.rs.gov.br/roteiro/85/rota-missoes Acesso em: 14 dez. 2020.

WIKIPEDIA. Reducciones jesuíticas. Disponível em:

https://es.wikipedia.org/wiki/Archivo:Reducciones.svg Acesso em: 13 dez. 2020 